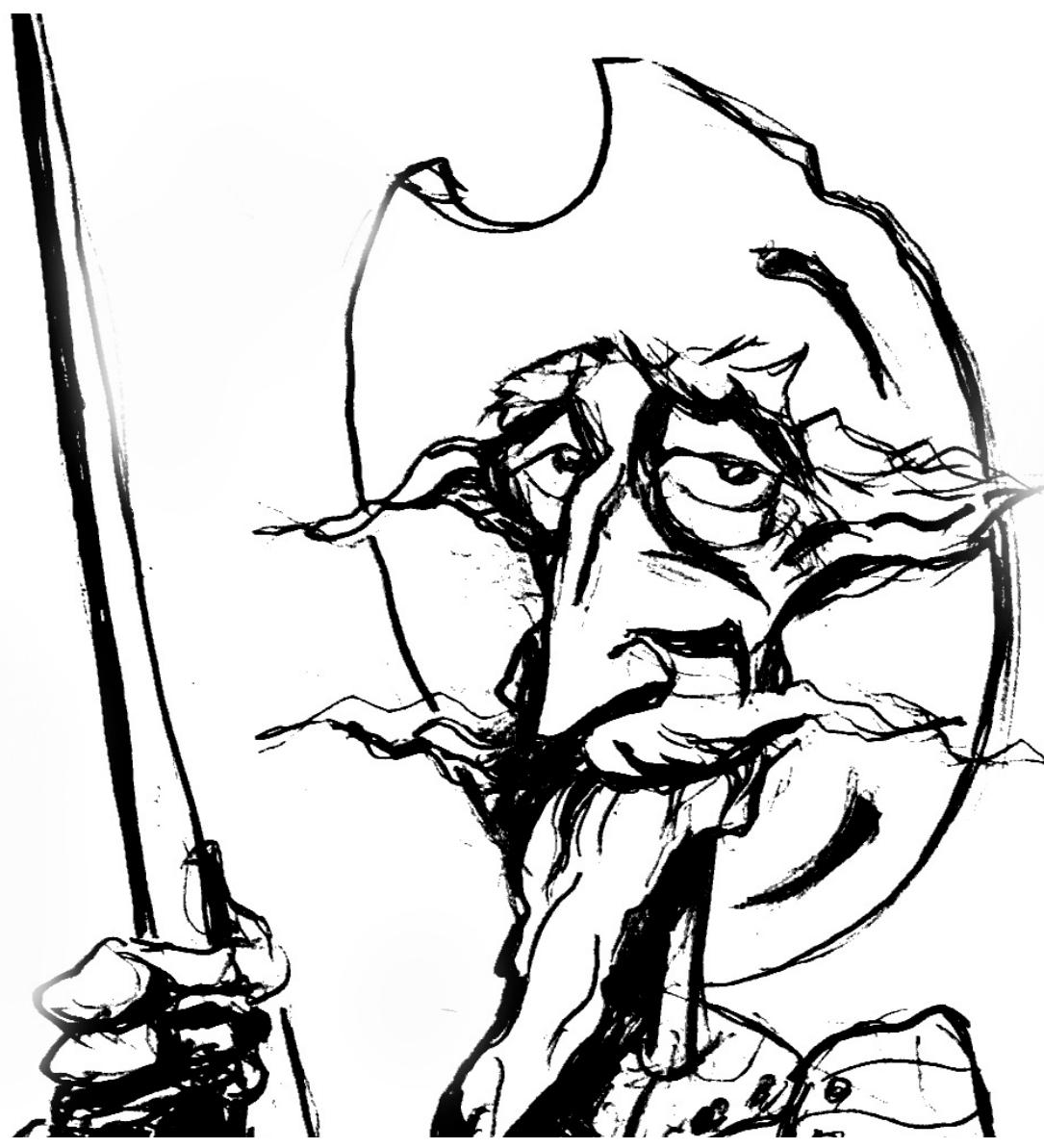

Repensando el anarquismo en América Latina. ¿Del nacionalismo metodológico a un giro transnacional incompleto?

[Ivanna Margarucci] 



\section{Repensando el anarquismo en América Latina. ¿Del nacionalismo metodológico a un giro transnacional incompleto?*}

\section{Rethinking Anarchism in Latin America. From Methodological Nationalism to an Incomplete Transnational Turn?}

IVANNA MARGARUCCI

Resumen

Durante el siglo pasado, el anarquismo en América Latina fue estudiado bajo la perspectiva del nacionalismo metodológico. Pese al mérito de estas producciones, omitieron importantes cuestiones relacionadas con la dinámica del movimiento anarquista latinoamericano. En las últimas décadas, la emergencia de la historia transnacional y la apropiación de su metodología por parte de los estudios libertarios, condujo a la publicación de nuevos trabajos que bajo este mismo enfoque abordan el anarquismo de la región. En el presente artículo, nos proponemos realizar un balance bibliográfico sobre las características e implicancias que tuvo el giro transnacional en dicha historiografía, considerando sus aportes, su incidencia en el campo historiográfico y sus limitaciones, relacionadas con las geografías ausentes del mapa transnacional construido en base a esas investigaciones.

Palabras clave

Anarquismo; América Latina; Nacionalismo Metodológico; Giro Transnacional; Historiografía

\begin{abstract}
During the last century, anarchism in Latin America was studied under the perspective of methodological nationalism. Despite the merit of these productions, they omitted important issues related to the dynamics of the Latin American anarchist movement. In recent decades, the emergence of transnational history and the appropriation of its methodology by libertarian studies, led to the publication of new works that under this same approach address regional anarchism. In this article, we propose to make a bibliographic balance on the characteristics and implications that the transnational turn had in this historiography, considering its contributions, its incidence in the historiographic field and its limitations, related to the absent geographies of the transnational map constructed on the basis of those investigations.
\end{abstract}

Keywords

Anarchism; Latin America; Methodological Nationalism; Transnational turn; Historiography

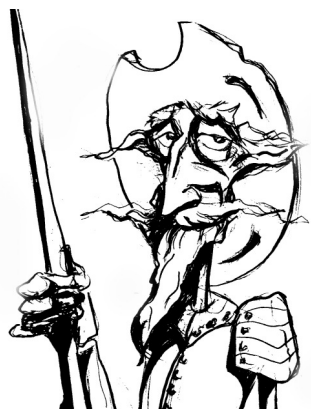

Recibido con pedido de publicación el 30 de noviembre de 2019

Aceptado para su publicación el 5 de marzo de 2020

Versión definitiva recibida el 20 de mayo de 2020

Ivanna Margarucci, Universidad de Buenos Aires, Centro de Documentación e Investigación de la Cultura de Izquierdas, Universidad Nacional de San Martín, Consejo Nacional de Investigaciones Científicas y Técnicas, Buenos Aires, Argentina; e-mail: ivannamargarucci@gmail.com

* Agradezco los comentarios de lxs evaluadorxs de la revista.

Esta obra se publica bajo licencia Creative Commons. Atribución-NoComercial-CompartirIgual $(\mathrm{cc})$ EY-NC-SA $\underline{4.0 \text { Internacional }}$

Margarucci, Ivanna “Repensando el anarquismo en América Latina. ¿Del nacionalismo metodológico a un giro transnacional incompleto?", Prohistoria, Año XXIII, núm. 34, dic. 2020, pp. 249-280. 


\section{Introducción}

En 2009, los historiadores Akira Iriye y Pierre-Yves Saunier compilaron un voluminoso diccionario editado por Palgrave Macmillan en Inglaterra. Se trataba de una obra monumental, cuyas entradas remitían a los más diversos temas, cronologías y geografías, estudiadas últimamente bajo los postulados de un enfoque metodológico emergente, no solo en la historia, sino en las ciencias sociales: el giro transnacional.

En la sección correspondiente a la letra " $\mathrm{A}$ ", encontramos la palabra "anarquismo." Un movimiento que, atravesado por un contexto político favorable, volvía a aparecer no solo en las luchas contra el neoliberalismo y la globalización, sino además en las producciones académicas. La definición esbozada por José Moya lo caracterizaba a este como "el primer y más extendido movimiento transnacional organizado desde abajo, sin partidos políticos formales"1 (Iriye y Saunier, 2009: 39). La importancia de estas palabras radica en que, a pesar del internacionalismo del movimiento libertario, su pasado había sido siempre estudiado dentro de los límites político-territoriales del Estado-nación. Así, la conceptualización que hace Moya da cuenta del inicio de una tendencia, relacionada con la incorporación de la historia transnacional en los estudios anarquistas, primero, de Europa, luego, de América Latina.

A diez años de haber sido publicado este diccionario, creemos que es tiempo de realizar un balance bibliográfico sobre las características e implicancias que tuvo este giro en la historiografía del anarquismo latinoamericano. Una reflexión que consideramos necesaria, ya que nos permitirá abordar críticamente las producciones previas, ponderar sus aportes metodológicos y temáticos, evaluar su incidencia en la ampliación y renovación de dicha historiografía y señalar cuáles son sus limitaciones.

Para ello, en el presente artículo indagaremos primero en el objeto de crítica de la historia transnacional: el nacionalismo metodológico, deteniéndonos en las definiciones y primeras impugnaciones realizadas desde la sociología en la década de 1970, así como en el proceso de convergencia entre historia, surgimiento del Estado-nación y nacionalismo metodológico, disciplina de la que también recibió cuestionamientos e intentos de propuestas superadoras. Luego, nos concentraremos en algunas generalidades de la historia transnacional, con el objeto de analizar específicamente la influencia que esta tuvo en los estudios anarquistas europeos y trazar algunas líneas metodológicas y temáticas que caracterizaron la aplicación del giro transnacional en dicha área de estudios. En los últimos apartados, nos enfocaremos en América Latina a partir de un balance bibliográfico que considera las producciones referidas al anarquismo continental desde la década de 1920 hasta nuestros días. En ellos analizaremos la historiografía del siglo XX,

\footnotetext{
${ }^{1}$ A menos que se indique lo contrario, las traducciones de las obras en inglés son de mi autoría.
} 
escrita bajo el paradigma del nacionalismo metodológico, y la historiografía reciente, en inglés y castellano, que utiliza el enfoque transnacional. Hacia el final del artículo, presentaremos un balance sobre los aportes y límites de la aplicación de esta nueva perspectiva. Al respecto argumentaremos que, debido a las geografías ausentes del mapa transnacional construido durante los últimos diez años en base a esas investigaciones -por ejemplo, el caso de Bolivia-, se trata todavía de un giro incompleto.

\section{Definiciones de un nacionalismo metodológico en debate}

Una misma idea atraviesa a las múltiples definiciones ensayadas de historia transnacional: su oposición al nacionalismo metodológico. La historia transnacional no fue sin embargo la primera en reaccionar contra este paradigma. De hecho, el concepto mismo de "nacionalismo metodológico" surge a raíz de una serie de impugnaciones realizadas por la sociología británica en la década de 1970.

El primero en acuñar el término, fue Herminio Martins cuando critica el rumbo tomado en los últimos treinta años por la sociología funcionalista. Martins define al nacionalismo metodológico como la "presunción general" impuesta en la práctica de la investigación social, según la cual la comunidad nacional es concebida como "la unidad terminal y condición límite para la demarcación de problemas y fenómenos para las ciencias sociales." Es decir, el nacionalismo metodológico se apoyaría según él en una identificación entre Estado, nación y sociedad, a partir de la cual las dos primeras categorías emergen como la unidad de análisis "estándar, optima e incluso máxima" (Martins, 1974: 276), en la medida en que contienen a la sociedad -la tercer categoría- en cuanto objeto de estudio.

En la misma época, otro sociólogo inglés, Antony Smith, retoma el concepto de Martins para interpretarlo de forma diferente. Sostiene una mirada más amplia acerca de lo que es la producción de conocimiento en general y sugiere que "el estudio de la 'sociedad' hoy en día se equipara, casi sin lugar a dudas, con el análisis de los estados-nación; el principio del 'nacionalismo metodológico' opera en todos los niveles de la sociología, la política, la economía y la historia de la humanidad en la era moderna." Asimismo, Smith considera que

"hay muchas buenas razones para proceder de esta forma, pero el fundamento teórico deriva gran parte de su fuerza de la aceptación de las concepciones nacionalistas, y contribuye en gran medida a reforzar esas concepciones. De esta manera, 'el sistema estado-nación mundial' se ha convertido en un componente estable y duradero de toda nuestra perspectiva cognitiva" (Smith, 1979: 191). 
En esta interpretación, el nacionalismo metodológico surge no tanto de una "moda intelectual" -como plantea Martins- sino de una "práctica institucional", a partir de la cual los propios Estados y en general el "sistema estado-nación mundial" están interesados en reforzar dicha concepción, observada por Smith desde una perspectiva histórica de larga data que cubre todo el siglo XX (Chernilo, 2006: 7-8).

Daniel Chernilo (2006: 9) conceptualiza bien la diferencia de sentido que hay entre estas dos "versiones de los argumentos del nacionalismo metodológico" y advierte que al pasar desapercibida, este aumenta su capacidad de naturalizar al Estado-nación, es decir, de ser concebido entre los investigadores como el principio ordenador natural y necesario de la modernidad.

La fortaleza de esta forma de acercarse y estudiar la sociedad se deriva entonces de su doble y sutil impronta, como operación metodológica a la vez que política. De ahí, que Chernilo concluya que "este es un problema que necesita ser abordado en el plano lógico e histórico al mismo tiempo." Resulta útil entonces preguntarnos, ¿cómo fueron tratados este y otros temas por la historia e historiografía?

\section{Nacionalismo metodológico, historia e historiografía}

El surgimiento de la historia como una "disciplina científica” no logró escapar la suerte de otras ciencias sociales, que, como ella, nacieron en un contexto fuertemente influenciado por el proceso de creación y consolidación del Estadonación durante el siglo XIX. En virtud de lo anterior, todas estas disciplinas, tomaron su realidad -la del Estado-nación- "como un constructo indiscutible que acabó en una compartimentalización de la ciencia en áreas o disciplinas 'nacionales'”' (Morcillo Espina, 2011: 700).

En el caso de la historia, la misión que le cupo dentro de esta división "disciplinar" del trabajo, fue la de forjar un relato sobre el pasado -y presentedel Estado-nación, diferente al del resto de los Estados vecinos que, contemporáneamente, se levantaban a su alrededor. La historia emergía así, con una vocación fuertemente legitimadora de ese orden estatal y nacional en ciernes, cuyo discurso exaltaba ante todo la excepcionalidad del recorrido histórico e identidad cultural seguido por el mismo. De esta manera, el marco utilizado en dicho relato no podía ser otro más que aquel provisto por las fronteras de los Estados en cuestión -fronteras a las que, con sus argumentos sobre grandes hombres y guerras victoriosas, también venía a apuntalar-.

A comienzos del siglo XX, desde las trincheras de la "Escuela" de Annales, asomaron las primeras críticas acerca del rol y horizonte analítico que desde sus inicios le correspondió la historia. 
La primera generación de esta corriente surgida en Francia en un contexto de crisis política y profunda renovación social y cultural, vino a poner en cuestión el interés exclusivo del quehacer historiográfico en la historia política y militar. En su reemplazo, propuso reencauzarlo por las sendas de la "historia global", que traducida a la práctica, implicaba abordar de forma articulada la dimensión económica, social, política y cultural de un problema, de una porción del pasado de la humanidad.

La que proponen los annalistas, es también una "historia global" porque "ensancha los territorios de análisis del historiador y [...] recrea el vínculo del tema analizado con la totalidad o totalidades que le son correspondientes" (Aguirre Rojas, 2005: 27). Una historia fundamentalmente comparada, que según March Bloch (1992: 87-88) nos lega una "enseñanza clara e imperiosa" y un "sueño": "romper los compartimientos topográficos perimidos [las fronteras de los Estados, aclara más adelante] en los que pretendemos encerrar las realidades sociales; no están hechas a la medida del contiendo que tratamos de forzar en ellas." Una "ingenuidad", un "anacronismo", un "error de fondo" subsistente, "pues ¿dónde se ha visto que los fenómenos sociales, en cualquier época que sea, hayan frenado unánimemente sus desarrollos en los mismos límites, que serían, precisamente, los de los dominios políticos o los de las nacionalidades?" Para "salir de la artificialidad" que encierra este ejercicio, Bloch sugiere tomar a la realidad social como punto de partida para "encontrarle su marco geográfico propio, determinado no desde afuera sino desde adentro. Investigación dificultosa, que exigirá mucha prudencia e infinitos tanteos. Negarse a enfrentarla sería una confesión de pereza" remata el fundador de Annales en 1928.

Pese al señalamiento de lo anterior y la incursión de esta escuela en algunas perspectivas novedosas (por ejemplo, las escalas de espacio-tiempo de Fernand Braudel [1949]), en general, no logró superar el nacionalismo metodológico criticado. Como argumentan Carmen De la Guardia y Juan PanMontojo (1998: 28), Annales (al igual que otras corrientes que la sucedieron, como la historiografía marxista británica, la historia social alemana y norteamericana) reintrodujo "los apriorismos nacionales expurgados cuidadosamente" a través de la construcción de problemas y planteamientos de preguntas "desde perspectivas atrapadas por sus contextos nacionales inmediatos." Por ejemplo, una de las obras más conocidas de Bloch (1924), en donde la comparación que realiza pone en diálogo dos casos definidos por el marco estatal y nacional de las monarquías de Inglaterra y Francia.

Más allá de los cuestionamientos procedentes de la historia y la sociología, el nacionalismo metodológico se mantuvo durante todo el siglo $\mathrm{XX}$ como un paradigma dominante. Recién a finales de siglo, aparecieron nuevas derivas historiográficas capaces de replantear, en la teoría y la práctica, aquella forma arraigada de construir escalas analíticas. 


\section{Superando el Estado-nación}

Teniendo en cuenta estos antecedentes, debemos advertir que el giro transnacional no supuso un movimiento innovador, ni tampoco en su momento se produjo de forma aislada. Más bien, debemos considerar junto a él, a otras corrientes que como un "continuum" de enfoques -contemporáneos y en diálogo-, compartieron una misma preocupación epistemológica: superar el nacionalismo metodológico. Nos referimos, de forma general, a la "Historia mundial", la "Historia global" (Mazlish y Buultjens, 1993; Mazlish, 1998), las "Historias conectadas" (Subrahmanyam, 1997) y las "Historias cruzadas" (Werner y Zimmerman, 2003), entre otras.

¿Cómo explicar este ataque conjunto y polifónico? A partir de la década de 1970, confluyeron diversas tendencias para que el Estado-nación dejara de ser un "constructo indiscutible", y con ello, las "disciplinas nacionales" perdieran también la centralidad ostentada desde el siglo XIX.

De un lado, la creciente internacionalización económica y política, asociadas al fin del keynesianismo, el avance del neoliberalismo y la globalización supusieron una ruptura de la unidad representada por los Estados nacionales, cuyas fronteras se vieron cada vez más rebasadas por la actuación de corporaciones multinacionales y órganos supranacionales. Cabe incluir también en este listado, la resistencia y la movilidad anti-colonial (Seigel, 2005: 63).

Del otro lado, la revisión de los ideales occidentales y los valores tradicionales de la modernidad que estuvieron en la base del "postmodernismo", llevaron a criticar la racionalidad como instrumento de conocimiento de la realidad y a postular la inexistencia de la universalidad encarnada en los grandes relatos. Esto condujo a la fragmentación y dispersión de las disciplinas -otrora consideradas científicas- y de sus modelos interpretativos y al surgimiento de "epistemologías regionales que obtenían su validez del objeto propio de estudio" (De la Guardia y Pan-Montojo, 1998: 20).

La historia, en este contexto, entra en crisis, de la que se sobrepone a partir de la "ampliación y [...] diversificación extrema, lo que da lugar a un panorama de extensión inmensa y de increíble riqueza" no solo de "contenido" (Morales Moya, 1992: 20) sino también, de categorías y metodologías nuevas para abordar esos objetos de estudios novedosos y variados. Esto supone asimismo un "estallido" de las unidades analíticas tradicionales: "los más amplios conjuntos sociales, las naciones, los países, las sociedades globales, se 'rompen'. En primer lugar, en elementos que adquieren ahora plena, total relevancia: ciudades, barrios, 'lugares de la memoria', del placer, del dolor o de la marginación, instituciones" (Morales Moya, 1992: 23). 
Con esta explicación, Antonio Morales Moya advierte bien el desplazamiento protagonizado por todas las derivas historiográficas mencionadas al inicio de este apartado como reacción contra el nacionalismo metodológico. Esto es, la unidad analítica no es la resultante de un a priori estado-céntrico en la que el objeto de estudio se asume auto-contenido y, por ende, se lo fuerza, sino que aquella es variable, construida y moldeada en virtud de las características del fenómeno que se quiere estudiar. El horizonte de análisis deja de ser uno, para ser creado y recreado, ampliado y reducido cuantas veces sea necesario, convirtiéndose en único.

Este es el sentido que De la Guardia y Pan-Montojo otorgan al concepto de "transnacional", cuando les toca definir el giro que en ese preciso momento estaba produciéndose en el campo historiográfico. ${ }^{2}$

“Transnacional no es pues sinónimo de gran escala, ni de comparaciones enormes, y no pasa por relegar al olvido a los estados nacionales [...] Tan o tan poco transnacionales pueden ser las microhistorias como las macrocomparaciones habituales de la sociología histórica. La transnacionalidad equivale en historia a ajustar el ámbito socioespacial a las cuestiones tratadas; un propósito que con frecuencia supone más bien determinar líneas de corte sugerentes, capaces de abrir nuevas vías de análisis, por cuanto que la mayoría de las redes y relaciones se caracterizan por su continuidad" (De la Guardia y Pan-Montojo, 1998: 28).

Según los historiadores, el enfoque transnacional no implica utilizar una escala amplia o una mínima que signifique, en los hechos, olvidar al Estadonación. Requiere más bien "ajustar" -"encontrar y determinar" como decía Bloch en 1928- el "ámbito socioespacial" -el "marco geográfico"- al objeto de estudio. Así, "la historia transnacional trata la nación como una entre una gama de fenómenos sociales a estudiar, en lugar del marco del propio estudio" (Seigel, 2005: 63).

De la Guardia y Pan-Montojo apuntan, además, algunas de las potencialidades inscriptas en el enfoque transnacional, desde el momento en que esta nueva forma de mirar, permitiría observar cosas no vistas antes, como ser, las conexiones de diversa índole que existen por encima de las fronteras, entre procesos o sujetos históricos -las cuales justifican, en última instancia, ese recorte-.

\footnotetext{
2 Simon Macdonald (2013: 2) advierte que el giro transnacional se produjo de forma más temprana y, por ende, tuvo mayor desarrollo en otras disciplinas, como ser la antropología y la sociología. En el caso de la historia, sugiere que su adopción fue tardía y la elaboración teórica "tendió a ser más acumulativa y pragmática que programática", de ahí, la relativa falta de trabajos que consignen propuestas metodológicas en torno a esta cuestión.
} 
Como se ve, estamos frente a fenómeno historiográfico reciente, aunque de gran potencia, si consideramos la variedad de temas trabajados bajo esta perspectiva (Iriye, 2013; Macdonald, 2013; Klaus Patel, 2015). Sus tópicos predilectos tienen que ver con la circulación transfronteriza, ya sea de personas (migraciones, diásporas y otras clases de desplazamientos internacionales compulsorios) como de ideas. La lente transnacional aparece aplicada, asimismo, sobre "viejos problemas", relacionados con las categorías de clase (movimiento obrero) o de etnia (racismo y antirracismo), y nuevos intereses temáticos, por ejemplo, la globalización o los derechos humanos. El arco temporal escogido remite a una cronología cuyo punto de partida se sitúa a mediados del siglo XIX y abarca un amplio espacio conformado no solo por Europa y el mundo atlántico, sino también Asia y el área del Pacífico. Las decenas de entradas que aparecen en las 1.267 páginas del diccionario de historia transnacional compilado por Iriye y Saunier (2009), constituyen una buena muestra de la amplitud temática, cronológica y geográfica de lo que para este momento era también ya un giro historiográfico.

\section{La historia transnacional, trabajadores y anarquismo}

Como señalamos, la clase trabajadora fue una de las protagonistas de este movimiento renovador, siendo abordada no solo por la historia transnacional, sino también desde el enfoque de la "Historia Global del Trabajo", que se constituye como tal a partir de los planteos e investigaciones pioneras de Marcel Van der Linden (2002 y 2008) y su equipo del Instituto de Historia Social de Ámsterdam.

De este modo, en un momento en que la investigación sobre la historia del trabajo había disminuido su fuerza al extremo de ser considerada como un objeto para anticuarios (precisamente, a causa de los cambios introducidos por el neoliberalismo, la globalización y el postmodernismo) (Van der Linden, 1993), esta consiguió revigorizarse, en parte, gracias a estas nuevas perspectivas. Quizás esto tenga que ver con que, tanto en la Historia Global del Trabajo como en la historia transnacional, no solo se plantean escalas analíticas diferentes a las tradicionalmente usadas, construidas en base al carácter internacional e internacionalista del movimiento obrero, sino que, además, ese objeto de estudio se ve redefinido en función del marco amplio en el que se desenvuelve su estudio.

En este escenario, ¿qué podemos decir acerca de la historia transnacional y su forma de abordaje del movimiento anarquista?

Históricamente el anarquismo fue estudiado por las ciencias sociales bajo la perspectiva del nacionalismo metodológico. Consideremos, a modo de ejemplo, las clásicas historias generales de George Woodcock (1962), Daniel Guérin (1970) y Peter Marshall (1993). Paradójicamente, el marco geográfico 
ponderado por estos y otros autores para acercarse al pensamiento y movimiento ácrata, ha sido aquel conferido por las fronteras del Estado-nación, aun cuando este abrazó una causa que negaba la división en naciones y se proponía como horizonte revolucionario destruir ese Estado. Lo que es más, en su momento de auge -que, grosso modo, podemos situar entre las últimas décadas del siglo XIX y las primeras del XX-, alcanzó una escala de proyección y desarrollo internacional, tanto en lo que atañe a la difusión y recepción de las ideas como a la organización y praxis, de un sujeto en esencia global: los "oprimidos del mundo."

En la misma década en que el nacionalismo metodológico era definido por la sociología británica y, como tal, comenzaba a ser cuestionado, desde Italia, el historiador y activista Giampietro Berti (1975: 49) introdujo una preocupación análoga en relación a los estudios libertarios, al advertir la desconexión existente entre objeto de estudio y unidad de análisis y señalar que frente a la "no-historia" del anarquismo elaborada por los "historiadores del poder", "es necesario volver a llevar al anarquismo a su múltiple extensión espacial que se identifica con su peculiar carácter internacionalista, reexaminándolo además prospectivamente en el arco global de su desarrollo; es decir hay que restituirle los caracteres espacio-temporales que le son propios."

Esta advertencia, no tendrá eco historiográfico hasta un buen tiempo después, cuando la historia transnacional llegue por otra vía a la misma conclusión que Berti y los estudios anarquistas, en un contexto de crecimiento asociado a la vuelta del anarquismo a las calles (Hirsch y Van der Walt, 2010: 396-398; Hirsch, 2011: 7), se apropien progresivamente de su metodología.

Los primeros en realizar este ejercicio fueron Benedict Anderson (2005[2008]), Constance Bantman (2006) y Davide Turcato (2007) en un libro y dos artículos escritos en inglés. En ellos los autores reproducen el interés de la historia transnacional por la circulación transfronteriza de personas e ideas. Anderson aborda las "coordinaciones" -conexiones transnacionales- existentes entre la lucha anticolonial filipina y cubana con el anarquismo europeo, Bantman estudia las redes "informales" tejidas entre el anarquismo inglés y francés a través del Canal de la Mancha entre 1880 y 1914 y Turcato analiza las relaciones de reciprocidad mantenidas en el mismo período por el movimiento anarquista italiano internacional y local, a partir del flujo de militantes, recursos e ideas y la integración organizacional. La importancia de los dos últimos, tiene que ver con que a partir de esos estudios de caso, los autores reflexionan en torno a las potencialidades de trasladar el giro transnacional a los estudios libertarios. En sus palabras, esta perspectiva era capaz de revelar la "importancia no reconocida de los esfuerzos informales [transnacionales], especialmente con respecto a la transmisión de ideas políticas" por fuera de las instituciones formales (Bantman, 2006: 962) y de forma más general, los repertorios de tácticas y estrategias del movimiento anarquista a nivel 
internacional junto a sus patrones de continuidad en el plano local, de lo cual Turcato se vale para rebatir algunas interpretaciones bastante difundidas y sesgadas sobre aquel (como ser, la tesis del milenarismo anarquista propuesta por Eric Hobsbawm [1959]).

La producción historiográfica sobre anarquismo transnacional dio un verdadero salto en la década siguiente, cuando se publicaron las primeras obras en las que se abordó sistemáticamente la problemática.

Turcato (2012) y Bantman (2013) reaparecieron en la década de 2010 como autores de dos libros que marcan un punto de llegada en las investigaciones presentadas en los artículos previos y sus tesis de doctorado, defendidas respectivamente en 2009 y 2007. El énfasis puesto en el carácter transnacional del anarquismo persiste aquí, no tanto como problema de indagación metodológica, sino como enfoque utilizado en dichas pesquisas para tratar los sujetos (Errico Malatesta) y los casos concretos (el movimiento anarquista italiano, los movimientos anarquistas francés e inglés) objeto de su interés.

De forma paralela, Constance Bantman compiló junto a otros dos historiadores -David Berry (2010) y Bert Altena (2015 [2017])-, un par de libros que compartían una serie de características similares. Se trata de obras colectivas, que reúnen ponencias inicialmente presentadas y discutidas en algunos paneles de dos eventos científicos organizados en el Reino Unido entre 2008 y 2012 -la I Anarchist Studies Conference (Loughborough, Inglaterra) y IX European Social Science History Conference (ESSHC) (Glasgow, Escocia) -.

Lo interesante de estos trabajos es, de un lado, la diversidad de temas y problemas pensados en clave transnacional que aparecen en cada uno de los capítulos individuales, y del otro, las consideraciones teóricas y metodológicas que se presentan tanto en las introducciones como en esos capítulos.

A diferencia de lo que habría sucedido con la adopción del giro transnacional por parte de la historia, la aplicación de esta perspectiva en los estudios anarquistas no parece haber sido un avance que se dio "a tientas", en base solo a la empiria de las investigaciones, sino que este estuvo acompañado por reflexiones que emergieron del diálogo e intercambio entre pares sobre cuestiones nodales. Por ejemplo, se destacan como preocupaciones de ambos textos, tratar de entender la circulación transfronteriza, en función de sus múltiples manifestaciones, causas y efectos; pensar lo transnacional a partir de la articulación de diferentes niveles analíticos -lo individual/lo local, lo nacional y lo transnacional; incorporar como parte de los análisis la dimensión biográfica y el método comparativo, con el objeto de poder dar cuenta de las redes (en oposición a las instituciones formales), las conexiones y las influencias mutuas entre esos distintos niveles-. 
Para 2015, año de edición del segundo libro, el movimiento anarquista y sindicalista anterior a la Primera Guerra Mundial había demostrado "ser un campo de investigación extremadamente productivo para los historiadores transnacionales." El balance realizado en la introducción del mismo, además de referirse a los aspectos señalados en el párrafo anterior, refiere algunas "limitaciones e implicaciones problemáticas de este concepto", siendo que las contribuciones publicadas en la obra se proponían "continuar añadiendo matices y complejidades en nuestro entendimiento del transnacionalismo" (Bantman y Altena, 2017: 3 y 5). Los compiladores, autores de este estudio preliminar, consideran, por ejemplo, la creciente opacidad del concepto, la necesidad de elegir cuidadosamente y combinar las escalas de análisis e incluir dentro de los nuevos estudios el rol jugado por el Estado y la nación (olvidados, quizás, demasiado rápidamente), conjuntamente con la identidad nacional, el nacionalismo, el patriotismo -e incluso, el racismo y antisemitismo- en la configuración del anarquismo de preguerra como movimiento transnacional. En este punto, es importante recuperar el llamado de atención hecho tanto aquí como en los capítulos que tratan estos temas, acerca de no dar por sentado el internacionalismo anarquista, lo cual implicaría, en última instancia, caer en el mismo error (la desconexión entre objeto de estudio y unidad de análisis) que se le criticaba al nacionalismo metodológico.

Otra cuestión que es preciso tener en cuenta, planteada en las introducciones de los libros, está ligada al sesgo eurocéntrico y el carácter geográficamente limitado de los artículos compilados en ellos. Este sesgo surge, en verdad, de una larga trayectoria de producción historiográfica concentrada casi exclusivamente en la región del Atlántico del Norte, en particular, Europa occidental y Estados Unidos, como se advierte en las obras arriba citadas de Woodcock, Guérin y Marshall, entre otras (Hirsch y Van der Walt, 2010: XXXIX). No obstante, revisando sus respectivos índices, puede advertirse que si en el primero, todos los capítulos refieren al cruce de experiencias dentro del ámbito del anarquismo europeo, el segundo abre el panorama hacia Sudamérica (con las contribuciones de Isabela Felici en la que hace algunas alusiones a los inmigrantes italianos en Brasil y Argentina y de Raymond Craib que trata sobre la figura del "anarquista sedentario" Casimiro Barrios en Chile), lo cual pone de manifiesto la progresiva ampliación espacial del giro transnacional desde el norte hacia el "sur global."

En función de los análisis previos y la última constatación, corresponde ahora trasladarnos a América Latina e indagar en el curso que siguieron los estudios anarquistas sobre la región, antes y después de dicho giro. 


\section{Un mosaico de expresiones nacionales}

Si recorremos la literatura que se dedicó a estudiar el pasado libertario de Latinoamérica, encontramos algunos trabajos iniciales cuyo registro oscila entre lo erudito y lo ensayístico, como ser, aquellos escritos por el militante e historiador del anarquismo Max Nettlau entre fines de 1920' y comienzos de 1930' republicados en la década de 1970 (Nettlau, 1972 y 1975)-. Al avanzar el siglo, mientras se conformaba el campo de los estudios latinoamericanos (Tinsman, 2007: 80-81), las producciones dedicadas a este tema viraron hacia la academia. A pesar de proceder de diferentes disciplinas (la literatura, la filosofía, la sociología y la historia), compartieron todas ellas un mismo objetivo: echar luz sobre la historia del anarquismo en América Latina, para lo cual se dieron a la tarea de reconstruir algunas experiencias del movimiento ácrata y recuperar sus fuentes y documentos (Méndez Pacheco, 2012). Ejemplo de ello es el artículo de Sarah Fanny Simon (1946) y los libros de Alfredo Gómez Müller (1950 [2009]), David Viñas (1983), Ángel Cappeletti y Carlos Rama (1990), Ángel Cappeletti (1990) y Luis Vitale (1998), que tuvieron un gran mérito conjunto: rebatir el eurocentrismo de la historiografía canónica y resituar en el mapa del anarquismo a Latinoamérica.

Sin embargo, desde su metodología, estos trabajos compartieron algunas premisas con dicha historiografía. Durante el siglo pasado, el anarquismo latinoamericano fue estudiado a partir de la sumatoria de sus "expresiones nacionales" -el movimiento anarquista "en" Argentina, "en" Uruguay, "en" Brasil, etc.-, sin ser replanteados ni cuestionados los límites físicos y conceptuales derivados de esa escala analítica. Esto resulta problemático, no por la mera cuestión de reproducir acríticamente dicha metodología, sino además por sus consecuencias epistemológicas, pues esos estudios acabaron por perder de vista algunas particularidades del proceso histórico regional, tanto en lo que se refiere al contexto general, como al fenómeno anarquista en particular.

Por ejemplo, ninguno de ellos problematiza el hecho que la construcción de los Estados nacionales de la región coincidió -al menos, en algunos casos- con la aparición del movimiento obrero y sus primeras manifestaciones políticas, bajo banderas socialistas o anarquistas. Se habla entonces de los inicios del anarquismo argentino a fines de siglo XIX, sin antes responder una pregunta básica, a saber, qué era en ese momento concretamente el Estado o la nación argentina. El surgimiento del Estado-nación en Latinoamérica sería entonces un asunto de poca relevancia para entender la emergencia del anarquismo, pero paradójicamente la variable estatal (la transformación del Estado, de su matriz oligárquica a una "nacionalista-populista") resulta una clave explicativa de primer orden para comprender el declive del movimiento libertario a comienzos de la década de 1930 (Gómez Müller, 2009: 227; Cappeletti y Rama, 1990: XIII). 
En relación específicamente con el anarquismo, las anteojeras puestas por el estrecho marco del Estado-nación distorsionaron la mirada de esta historiografía de varias maneras.

En primer lugar, los autores de los anteriores trabajos solo fueron capaces de ver una única forma de vinculación posible, esencialmente pasiva, entre el "viejo" y el "nuevo" continente, cuyos vínculos habrían comportado el desplazamiento de personas y la "importación" de ideas, en un momento preciso (el momento fundacional del anarquismo) y en una sola dirección (desde Europa hacia América). El corolario que se deriva de estas interpretaciones, es que no habrían existido relaciones entre los movimientos libertarios locales. ${ }^{3}$ Ya desde la disposición gráfica del texto en los artículos y libros queda plasmada tal ausencia: en ellos, cada caso nacional aparece editado como un acápite o un capítulo por separado. Así, esas expresiones nacionales del anarquismo, reunidas en un conjunto que se asemeja a un mero listado de países, son pensadas como "compartimentos estancos", los cuales habrían seguido un desarrollo autónomo, más vinculado a Europa -por sus orígenes- que a América Latina.

Las anteojeras no solo orientan la mirada de la forma señalada. Además, no dejan atender las modalidades y vectores de circulación y difusión del anarquismo al interior del continente entre lo que vendrían a ser aquellas expresiones nacionales "compartimentalizadas" y obturan, en definitiva, la comprensión de la propia dinámica del movimiento anarquista latinoamericano.

Estas distorsiones provocadas por el nacionalismo metodológico dejan sin explicación plausible varios de los países que aparecen en la lista, por ejemplo, Bolivia. Un caso nacional bastante particular, donde hubo anarquismo, pero debido a su condición mediterránea, pocos inmigrantes. ${ }^{4}$ Donde el arribo de las

\footnotetext{
${ }^{3}$ El único texto que de manera temprana repara sobre la existencia de relaciones entre los anarquismos del espacio latinoamericano es el de Simon (1946). En él, ella da algunas pistas sobre la correspondencia e intercambio de periódicos que circulaban en las redes informales y los ensayos que llevaron a la constitución de instituciones formales como la Asociación Continental Americana de Trabajadores (ACAT) en 1929. Lo llamativo es que ninguno de los otros autores, a pesar de citar el trabajo de Simon, retoman y profundizan esta línea de análisis. ${ }_{4}^{4}$ Como resultado de la Guerra del Pacífico (1879-1883), en la que Bolivia y Perú fueron derrotados por Chile, la provincia boliviana de Antofagasta fue anexada al territorio chileno, lo que significó para el primer país perder no solo el valioso recurso del salitre, sino también la costa del Pacífico. Así Bolivia se convirtió en un territorio mediterráneo, sin conexiones directas ni con el Océano Pacífico ni con el Atlántico. Posteriormente, Bolivia sufrió otras pérdidas territoriales, ocurridas en las regiones de Acre y Chaco, tras los conflictos militares librados contra Brasil (la Guerra de Acre, durante 1899-1903) y Paraguay (la Guerra del Chaco, durante 1932-1935). El aislamiento geográfico resultante, se vio reforzado por la política ferroviaria boliviana. Las conexiones internacionales por ferrocarril se desarrollaron tardíamente para el tránsito de mercancías y mano de obra estacional hacia importantes mercados exteriores como Chile y Argentina (Ferrocarril Antofagasta-Oruro, 1892; Ferrocarril Villazón-Tupiza-Atocha, 1925), también como parte del tratado de paz con Chile (Ferrocarril Arica-La Paz, 1913), en lugar de estar asociadas a una política destinada a promover la inmigración y la colonización
} 
ideas anarquistas se dio de varias formas "indirectas", a través de las rutas abiertas por las mulas de los arrieros y las vías del ferrocarril. Rutas transitadas desde dos países vecinos, Chile y Argentina, por trabajadores (que iban y que volvían, no una, sino varias veces), activistas y un "submundo" más propio de la literatura que de la historia, esos hombres vagabundos y errantes -anárquicos hasta la médula- encarnados por los "crotos" y los "linyeras" (Margarucci y Godoy Sepúlveda, 2018).

En la medida en que la boliviana es una experiencia difícil de explicar, acaba siendo poco o mal considerada por la historiografía. Si bien seis de los ocho trabajos citados (Simon [1946], Nettlau [1972], Viñas [1983], Cappeletti y Rama [1990], Cappeletti [1990] y Vitale [1998]), refieren a este caso, ninguno le dedica una extensión considerable (comparado con el espacio que otorgan, por ejemplo, a la Argentina, Brasil o México ${ }^{5}$. Excepto dos textos, que introducen algunos datos originales a partir de la documentación consultada (Simon, 1946) o la prensa periódica acopiada y la correspondencia recibida (Nettlau, 1972), el resto no citan fuentes primarias y presentan errores y omisiones significativas. Una de ellas, claro, tiene que ver con los mecanismos a través de los que el anarquismo llegó a los Andes bolivianos.

De esta manera, a partir de la anterior literatura se alcanzó un "consenso historiográfico", acuerdo que reconoce solo algunos casos paradigmáticos mientras que desconoce otros también relevantes- y fechas precisas de surgimiento (las últimas décadas del siglo XIX) y de crisis (las primeras décadas del siglo $X X$ ), en lo que constituye un ejercicio de periodización -otra forma de compartimentación, ahora, del tiempo-, sino arbitrario, al menos demasiado general para dar cuenta de los desarrollos particulares del anarquismo en las distintas geografías del centro y sur de América.

El peso de dicho consenso puede incluso advertirse en obras de reciente publicación que se propusieron actualizar con nuevos enfoques y temas la historiografía del anarquismo en América Latina. Tal es el caso del libro compilado por Clara Lida y Pablo Yankelevich en 2012, Cultura y política del anarquismo en España e Iberoamérica, publicado luego del coloquio desarrollado en marzo de 2011 en el Colegio de México bajo coordinación de los compiladores. A pesar del acierto metodológico que hay detrás de la elección de un marco geográfico "transcontinental", planteado en función de la circulación de personas y de ideas desde España a América Latina y las similitudes y diferencias existentes entre los dos espacios en el plano de la cultura y la política anarquista,

extranjeras. Estos factores explican por qué durante las primeras décadas del siglo $\mathrm{XX}$, si comparamos con otros países latinoamericanos, Bolivia recibió una proporción muy pequeña de inmigración europea, poco significativa en términos de su peso demográfico y social dentro de la clase trabajadora urbana y rural.

${ }^{5}$ Véase, a modo de ejemplo, Cappeletti y Rama (1990), quienes en la primera parte del libro, dedican 48 páginas al caso de la Argentina, 68 a Brasil, 40 a México y 4 a Bolivia. 
el libro no logra romper del todo con la tradición de las producciones previas. Su propia estructura y la escala analítica y el contenido de los capítulos compilados se inscriben en el mismo registro del nacionalismo metodológico. Los casos presentes y ausentes de su índice, sufren de un desbalance similar al advertido en el libro de Cappeletti y Rama. Se trata de una obra que bien puede representar una suerte de transición, entre viejas y nuevas tendencias historiográficas.

\section{Redes y conexiones transnacionales anarquistas en América Latina}

El coloquio coordinado y el libro compilado por Lida y Yankelevich entre 2011 y 2012 sintetizan en verdad todo un clima de época, en el cual a diferencia de las décadas anteriores se advierte un creciente interés por el estudio de la historia social, política y cultural latinoamericana. Diversos factores, que van desde el contexto más global (la crisis del orden neoliberal y la emergencia de los llamados "nuevos movimientos sociales" y "gobiernos progresistas") hasta lo que se refiere estrictamente a las condiciones de producción académica (aparición de espacios e instancias de formación, aumento de financiamiento a investigaciones, organización de bibliotecas, archivos y repositorios digitales), convergieron para dinamizar los estudios sobre el movimiento obrero, las izquierdas y los procesos revolucionarios del siglo XX y los nuevos actores en lucha del XXI. ${ }^{6}$

En este escenario, la llegada de la historia transnacional al estudio de nuestro continente lo hizo de la mano, ya no del neoliberalismo y la globalización, sino del intento de comprender la capacidad de las clases populares de la "periferia" para resistir el dominio del "centro" -Estados Unidos- (Weinstein, 2013: 4) y analizar los movimientos sociales que efectivamente opusieron resistencia a esos procesos (Keck y Sikkink, 1998; Almeida y Johnston, 2006). Progresivamente el giro transnacional alcanzó a otras temáticas. Su aplicación en el campo que se estaba constituyendo, el de la historia de los trabajadores y las izquierdas, no fue la excepción a la regla. Tampoco lo fueron dentro de este, los estudios anarquistas.

Un hecho que, en 2010, sintetiza y expresa los anteriores cambios, es la aparición en Europa y en Estados Unidos, de un importante libro editado por el historiador norteamericano Steven Hirsch y el sociólogo sudafricano Lucien

\footnotetext{
${ }^{6}$ Sobre esta cuestión no existe todavía un balance bibliográfico acabado. A falta de este, en su editorial del número 18, la revista Políticas de la Memoria, recuerda el desplazamiento que sufrió la agenda historiográfica de la historia de los trabajadores y las izquierdas y da cuenta de la "expansión inédita" que se produjo a partir del 2000, en nuestro país y en América Latina en general, en torno a la investigación y producción académica sobre estos temas. Una pauta cuantitativa de esta expansión puede dárnosla la cantidad de libros y artículos aparecidos en los últimos años. Véase, a modo de ejemplo: Guevara, 2013; Stoessel, 2014; Pipitone, 2015; Becker, 2017 y Camarero y Mangiantini, 2018.
} 
Van der Walt, bajo el título Anarchism and Syndicalism in the colonial and postcolonial world, 1870-1940. Un exhaustivo trabajo que desde el largo aliento busca examinar "la historia, influencia, aspiraciones y acciones del anarquismo y sindicalismo en el mundo colonial y poscolonial desde la década de 1870 hasta la de 1940" (Hirsch y Van der Walt, 2010: XXXI).

Las experiencias desarrolladas en los diez estudios de caso sobre África, Asia, Europa del Este y América Latina se sitúan en una geografía prácticamente inexplorada en la literatura anarquista de habla inglesa y en un contexto histórico caracterizado por el desarrollo del "imperialismo, el capitalismo industrial y la formación del Estado", cuyos "circuitos y centros" "proveyeron los nexos en los que su némesis, los anarquistas y sindicalistas, emergieron" (Hirsch y Van der Walt, 2010: XXXVI). El período de la "primera globalización", que se vio acompañado además de una revolución en el transporte y las comunicaciones, de migraciones masivas y grandes desplazamientos de fuerza de trabajo, constituye pues el marco para el surgimiento de estos dos movimientos, pensados fundamentalmente como movimientos transnacionales.

El espacio latinoamericano está representado con cuatro entradas de diferentes autores. Hirsch se dedica a estudiar la experiencia del anarquismo del Perú, abordada desde su capital, Lima, y el sur urbano y rural de ese país. Kirwin Shaffer se concentra en las redes transnacionales montadas por el anarquismo desde Cuba hacia Centroamérica y el sur de los Estados Unidos. Geoffroy de Laforcade repite esta operación para el caso argentino, focalizándose sobre el gremio de estibadores y marineros. Edilene Toledo y Luigi Biondi analizan el sustrato transnacional sobre el que se asentó la formación del movimiento anarquista y sindicalista de San Pablo en Brasil.

Como se ve, los capítulos intentan articular de forma equilibrada las escalas locales y nacionales en donde se plantean los estudios de caso con las redes de "conexiones supranacionales y [...] flujos multidireccionales de ideas, personas, finanzas y estructuras organizativas" (Hirsch y Van der Walt, 2010: XXXI) formales e informales, además de las campañas de solidaridad y rituales comunes que dieron vida a aquellos movimientos. Al mismo tiempo, como novedad, analizan la forma en que los anarquistas y sindicalistas conjugaron ese internacionalismo con las "tendencias seccionales que lo socavaban" (Hirsch y Van der Walt, 2010: XXXVI): sus posicionamientos sobre la "cuestión nacional" (lo que incluye temas como la identidad nacional y étnica y las demandas de autodeterminación e igualdad racial) y asociado a esto, sus intervenciones en las luchas contemporáneas contra el colonialismo e imperialismo.

El estudio es igualmente valioso por el prólogo -que lleva la firma de Benedict Anderson- y el extenso estudio introductorio y el cierre escritos a dos 
plumas por Hirsch y Van der Walt. En ellos, plantean una visión de conjunto que, a través de la generalización y la comparación, pone en diálogo las contribuciones individuales, al tiempo que introducen algunas reflexiones sugerentes en torno al surgimiento -"simultáneo y transnacional", "global” y "multidireccional" - del anarquismo y su declive. Un proceso en verdad matizado, "relativo", causado entre otras variables, por el fin de la era de la "primera globalización" entre 1930 y 1940 y la emergencia de un sistema dominado por el Estado-nación y el nacionalismo económico. La caída de este sistema en los 90' con el neoliberalismo, la "segunda globalización" y el desdibujamiento de esa forma particular de Estado, habrían estado en la base del resurgimiento de un anarquismo que, en sus postulados y prácticas principales, no constituye para los autores una novedad respecto de las experiencias libertarias desarrolladas en el mundo colonial y poscolonial de fines de siglo XIX y comienzos del XX (Hirsch y Van der Walt, 2010: 396-412).

Los aspectos nodales del libro, nos remiten a una nueva manera de pensar y estudiar el anarquismo latinoamericano, podríamos decir, desprovista de las anteojeras que distorsionaron la mirada de la historiografía del siglo XX.

Tanto estas ideas fuerza, como algunos temas y autores de sus capítulos (Cuba y Argentina con Shaffer [2011] y de Laforcade [2011]) se repitieron en 2011 en el dossier titulado "Transnational Anarchism in Latin American" de la revista Estudios Interdisciplinarios de América Latina y el Caribe (Universidad de Tel Aviv, Israel). Steven Hirsch advierte en el texto introductorio al dossier "la profunda revisión histórica" que actualmente estaba experimentando "la compleja historia del anarquismo global", revisión de la que Latinoamérica como era ya evidente- no había quedado al margen.

De forma paralela, las inquietudes de estos investigadores (Hirsch, Shaffer y de Laforcade) y de otros quedaron plasmadas en los eventos científicos de la época, lo cual nos muestra como a través de las publicaciones y los congresos (que no pueden pensarse como dos instancias separadas de producción académica) la historia transnacional se fue abriendo, de a poco, un nuevo espacio dentro de los estudios anarquistas. ${ }^{7}$

\footnotetext{
7 En 2010, Hirsch y Van der Walt organizaron el simposio "Transnational Anarchism in Latin America and the Caribbean, 1890s-1920s" en la VIII ESSHC (Gante, Bélgica). En la edición previa de 2008, habían participado de uno sobre anarquismo en perspectiva comparada con los mismos temas -Perú, Cuba y Argentina en clave transnacional. El repertorio de ponencias sobre estas cuestiones se amplió a partir de 2011, en la mesa temática de la II Annual North American Anarchist Studies Network Conference (Toronto, Canadá). A comienzos de 2012, se realizó un panel similar en su III edición (San Juan, Puerto Rico) y a mediados de año, Hirsch y Shaffer instalaron la temática en una reunión científica de grandes proporciones, el International Congress of Americanists (ICA) 52을 (Viena, Austria), con el simposio "Transnational Anarchism in the Americas, 1870-1940" en la cual participaron expositores norteamericanos, europeos y, ahora también, latinoamericanos. Este simposio se reeditó bajo diferentes títulos y
} 
En los años siguientes, mientras en América Latina comenzaba a ser adoptada in situ esta perspectiva, por ejemplo, para seguir estudiando las bases transnacionales de poderosos movimientos anarquistas locales como el de San Pablo (Godoy 2013), desde el norte continuaron llegando importantes contribuciones.

En 2013 se editó el dossier de la revista española Alcores (Fundación Fermín Carnero, León) titulado "Las redes anarquistas transnacionales entre los siglos XIX y XX", bajo coordinación de Susana Sueiro Seoane. El dossier, además de ser una muestra del avance de esta clase de estudios en España (todos los autores, excepto uno, Turcato, son de nacionalidad española y sus artículos tocan temas con eje en ese país), trae una contribución de Amparo Sánchez Cobos (2013) sobre las relaciones transnacionales que unieron a los anarquistas de España y Cuba entre 1900 y 1925. Se trata del primer trabajo escrito en lengua española que utiliza esta perspectiva para abordar un caso latinoamericano.

Un año después fue publicado el dossier "The Whole World Is Our Homeland: Italian Anarchist Networks in Global Context, 1870-1939" en la revista digital Zapruder World (Odradek Edizioni, Roma, Italia) en el que se destaca el artículo de Shaffer (2014) -al igual que Sánchez Cobos especialista en Cuba y Centroamérica-. En él, plantea algunas reflexiones metodológicas interesantes sobre el estudio de las redes transnacionales -necesariamente enraizadas en nodos locales o nacionales- e ilustra una serie de dimensiones de esas redes en las Américas, relativas a su geografía, sus formas particulares de funcionamiento y la importancia del canal de Panamá como centro de desarrollo de aquel que el autor denomina el "panamericanismo" anarquista.

El mismo Shaffer y de Laforcade editaron en 2015 el libro In Defiance of Boundaries. Anarchism in Latin American History. Como su título lo indica, es una obra dedicada exclusivamente a Latinoamérica, concebida originalmente como un proyecto de compilación "país por país", objetivo que los editores acabaron descartando por considerarlo fútil. En su reemplazo, decidieron reunir en ella una serie de estudios que "desafiaran a las fronteras" -geográficas, cronológicas y temáticas- tradicionales y constituyeran aportes metodológicos y temáticos dentro de la que comenzaba a emerger como una renovada y dinámica área de estudios.

coordinaciones en las ediciones $53^{\circ}$ (2015) y $54^{\circ}$ (2018) del ICA, continuidad que evidencia la persistencia de una línea de trabajo llevada adelante por un grupo de investigadores, que con el paso del tiempo, se fue ampliando y diversificando temáticamente. Recientemente, en 2019, el II Congreso de Investigadorxs sobre Anarquismo(s) (Montevideo, Uruguay) incluyó en su programa una mesa sobre anarquismo transnacional, cuyo eje de discusión a partir de los trabajos presentados fue América Latina. 
Los historiadores norteamericanos cuestionan en la introducción del libro el nacionalismo metodológico que fuera moneda corriente en la historiografía del anarquismo latinoamericano durante el siglo anterior, por ser una forma de abordaje "contra-intuitiva" del internacionalismo ácrata e insisten sobre la necesidad de aproximarse al anarquismo a partir de múltiples escalas analíticas, que van desde lo local a lo transregional. En este enfoque, cobran un rol fundamental el género biográfico y el análisis del funcionamiento de las redes de difusión e intercambio -lo cual es objeto de indagación historiográfica y teórica de parte de los editores en la misma introducción (De Laforcade y Shaffer, 2015: 4)-.

Las secciones en las que está dividido el libro pueden pensarse de acuerdo a esa propuesta de recorte "multi-escala", siendo que la primera de ellas reúne las contribuciones planteadas en el nivel "más macro": las redes transnacionales construidas en base a pertenencias gremiales y "nacionales" (los cigarreros cubanos en La Habana y la Florida durante la segunda guerra de independencia [Daniel]), a áreas de trabajo fuertemente cosmopolitas y bien conectadas (la zona del Canal de Panamá [Shaffer]), a artefactos culturales comunes (la prensa "wooblie" en Latinoamérica [Rosenthal]) y a la solidaridad internacional (de los anarquistas de Argentina con los de España en tiempos de la Guerra Civil [Baer]).

La segunda sección remite la dimensión colectiva del trabajo y a la cultura, dos temas que recién en los últimos años vinieron a complementarse (producto del desbalance presentado por la vieja historiografía en favor del primer tópico). Los casos que se presentan sobre el "anarco-batllismo" en Uruguay (Peterson), las políticas culturales del anarquismo en Cuba (Shaffer), la experiencia militante y cultural del anarquismo en Río Grande do Sur, Brasil (Loner) y la resistencia anarquista entre los trabajadores astilleros de la Argentina (de Laforcade) aparecen desarrollados en un plano en el que se conjuga lo regional y lo nacional.

Finalmente, en la tercera sección, la escala en la que se sitúa la intervención del anarquismo en una serie de procesos de construcción identitaria va de lo individual a lo grupal -en diálogo, siempre, con ese marco regional/nacional-. Estos procesos remiten a temáticas e intersecciones novedosas, como ser, la cuestión de la identidad nacional en Costa Rica (DíazArias), la identidad indígena en el contexto de la revolución mexicana (England) y en el norte peruano (Hirsch), la alteridad representada en la figura del anarquista en Chile (Craib) y las identidad(es) de género en Argentina (Fernández Cordero).

Las anteriores contribuciones dan cuenta del crecimiento en autores y temas estudiados bajo la óptica transnacional en las siete "redes regionales" anarquistas identificadas por Shaffer (2014) que, según él, existieron entre 1890 
y 1920: la transatlántica, la costa este de América del Norte, el gran Caribe, la frontera Estados Unidos-México, la costa del Pacífico de Suramérica, los Andes y el Río de la Plata.

A partir de entonces, los trabajos continuaron multiplicándose, tendiendo a concentrarse en tres de esas áreas: la trasatlántica, la caribeña (además de los autores mencionados, debemos agregar la investigación en curso de José Julián Llaguno [2016 y 2019]) y la rioplatense.

En efecto, desde 2015, la última región adquirió un protagonismo central en esta clase de estudios, pensada no solo como una red en sí misma, sino como un espacio articulador de redes tendidas por el anarquismo con base en Buenos Aires y Montevideo, hacia Europa y América Latina. Un ejemplo de lo que Bantman y Altena (2017: 12) caracterizaban como una "red de redes."

James Baer (2015) publicó en Estados Unidos un libro en el que vuelve sobre la cuestión de los anarquistas inmigrantes en Argentina y España entre comienzos de siglo XX hasta la década de 1930, poniendo en evidencia el carácter multidireccional de los vínculos estrechos que conectaron los movimientos de ambos países.

Las producciones locales sobre el anarquismo argentino en perspectiva transnacional llegaron de forma relativamente tardía, de la mano de dos investigadores con un largo recorrido sobre este tema. Así, en 2017, releyeron o repensaron algunos actores o problemas de sus investigaciones a la luz de dicho enfoque.

Laura Fernández Cordero (2017) analiza en un artículo del Anuario de Estudios Americanos (Escuela de Estudios Hispano-Americanos, Sevilla, España) el "diálogo transnacional" entablado hacia América Latina por el periódico del anarquismo feminista Nuestra Tribuna. El diálogo reconstruido por Fernández Cordero permite ver los amplios nexos transnacionales que vincularon al grupo editor de la publicación con los movimientos libertarios del continente. La red tejida a instancias de estos, tiene la virtud de mostrar geografías poco consideradas anteriormente por la historiografía del anarquismo latinoamericano, como ser los casos de Chile, Perú y Bolivia.

Ese mismo año, Martín Albornoz publicó junto a Diego Galeano una serie de artículos en los que se proponen reconstruir las redes de vigilancia transnacional utilizadas para reprimir el movimiento anarquista argentino entre la última década del siglo XIX y la primera del XX. En ellas, Buenos Aires se destaca como punto nodal de esas redes montadas entre Argentina y España (Albornoz, 2017) y del espacio que los autores llaman el "atlántico sudamericano" (Albornoz y Galeano, 2017 y 2019). Esta investigación, que surge de un amplio trabajo de archivo en distintos países y el uso de fuentes primarias hasta ahora poco utilizadas en la historiografía del anarquismo (fuentes policiales y diplomáticas), resulta novedosa no solo por su 
metodología, sino también por el objeto de estudio, el cual no ha sido abordado de forma sistemática (sí quizás mencionada la necesidad de estudiarlo) por otros trabajos.

Finalmente, en 2018 se escribieron desde América Latina y Europa una serie de tesis de maestría y doctorado en historia que certifican la expansión y renovación aquí aludida. Sus preocupaciones, geografías y cronologías son diversas, lo cual habla de una ampliación que es también temática.

En Brasil, Eduardo Souza Cunha (2018) aparece como el autor de una tesis de maestría en la que se enfoca en la actividad editorial de los grupos anarquistas de Buenos Aires entre 1890 y 1905. Como en trabajos anteriores y posteriores, Cunha se preocupa por el carácter transnacional (Cunha 2017 y 2019; Cunha y Godoy, 2018) asociado a esta empresa y descubre las redes existentes entre esta ciudad y otras de Brasil, Estados Unidos e Italia que permitieron la edición y circulación de folletos, periódicos y libros ácratas. En el mismo país y año, Rafael Viana defendió una tesis de doctorado en la que utiliza de forma combinada el enfoque transnacional y el método comparativo para recuperar los diálogos, las similitudes y las diferencias entre las prácticas políticas del anarquismo en Argentina, Brasil y Uruguay, desarrolladas ya no en su momento "clásico", sino entre 1959 y 1985, bajo el influjo de la Revolución Cubana, las experiencias político-guerrilleras y las dictaduras locales (Viana, 2018).

También, la extensa investigación de María Migueláñez Martínez elaborada durante la última década sobre la figura de Diego Abad de Santillán (2013) y, a partir de él, las redes de difusión e intercambio que desde Argentina acercaron el espacio latinoamericano (2014) y europeo (2013a y 2014a), constituye el sustrato de su tesis de doctorado titulada Más allá de las fronteras. El anarquismo argentino en el período de entreguerras (2018). Tesis que logra, desde sus notables hallazgos (fruto del amplísimo corpus de fuentes con el que trabaja) y enfoque metodológico, redimensionar un objeto de estudio sobre el cual se pensaba que estaba todo dicho.

\section{A modo de balance. ¿Un giro incompleto?}

Es indudable que durante la última década se produjo una verdadera expansión en las producciones sobre el anarquismo latinoamericano, mensurable en libros, artículos y dossiers en revistas, tesis de posgrado, ponencias y simposios en congresos, etc. No se trata solo de una cuestión de cantidad, sino también del cambio cualitativo asociado a este crecimiento: el giro transnacional aplicado en las investigaciones, el cual permitió corregir la forma con la que tradicionalmente se lo observaba a aquel. Concretamente, las distorsiones causadas por el marco geográfico que proveía el nacionalismo metodológico, para estudiar un fenómeno internacionalista y antiestatista en las 
ideas, transfronterizo en sus prácticas. Si en el siglo pasado hablar del anarquismo era hacerlo dentro de las fronteras del Estado-nación, en el actual parece poco probable desconocer ese carácter transnacional, desde la historia y también la metodología.

Los aportes resultantes de este giro son significativos. Como hemos visto, aparecieron nuevos temas y problemas, se replantearon viejas cuestiones. Gracias a ello, la historiografía del movimiento anarquista en América Latina atravesó (y todavía atraviesa) un proceso doble, de ampliación y renovación. Asimismo, el mapa transnacional de ese movimiento es hoy mucho más complejo de lo que era hace treinta años.

La pregunta que surge en este estadio de producción historiográfica tiene que ver con el diálogo existente entre la gran cantidad de trabajos escritos en inglés y aquellos publicados durante los últimos años en España y América Latina en castellano y portugués. Todo indica que, a pesar de algunas excepciones, no existe un verdadero intercambio entre ellos, pues muchas de estas producciones más recientes no han logrado superar la barrera impuesta por el idioma anglosajón, el cual persiste como "lingua franca" de la academia.

Asimismo, de una lectura crítica del corpus de trabajos analizados, emerge otra importante cuestión. El desbalance que hay entre los estudios vinculados a las tres áreas destacadas (la transatlántica, la caribeña y la rioplatense) en desmedro de otras. El Océano Atlántico versus el Pacífico. Parecería ser entonces que el giro que se produjo es un giro incompleto, que se dio pero a medias.

Señalar esto no implica relativizar la importancia de los trabajos enfocados sobre el área de los Andes tal como la define Shaffer (2014), pero estos, debemos advertir, son muy pocos. Contamos solo con una tesis de maestría que, sin hablar de transnacionalidad, aborda de forma general las relaciones entre las organizaciones anarquistas y socialistas de Argentina y Chile (Giner, 2011) y dos artículos que se concentran, ahora sí desde ese enfoque, en los vínculos Chile-Perú, tendidos a partir del activismo y la solidaridad de los trabajadores marítimos, quienes actuaron bajo el influjo de la International Workers of the World en la costa de los dos países (Hirsch, $2010 \mathrm{y}$ Savala, 2019).

En este escenario, cabe volver a preguntarnos por Bolivia, un país ausente de dicha cartografía anarquista, lo cual, en cierto sentido, pone de relieve como las nuevas interpretaciones se apoyan y terminan reproduciendo al menos en este aspecto- el consenso historiográfico al que arribó la historiografía del siglo XX. A pesar de la discusión y la ruptura epistemológica establecida entre el nacionalismo metodológico y el transnacionalismo, hay aquí una continuidad temática y una predilección geográfica entre ambos enfoques cuando se trata de estudiar el pasado anarquista latinoamericano. 
En los últimos años, intentando llenar este vacío, junto al historiador chileno Eduardo Godoy Sepúlveda, hemos planteado y desarrollado algunas líneas interpretativas sobre la difusión del anarquismo en Bolivia durante las primeras décadas del siglo XX. Para ello, hemos considerado los movimientos de trabajadores y activistas producidos en torno al espacio transfronterizo del "Norte Grande", que abarca el norte chileno y argentino y el altiplano boliviano, y las -hasta entonces- desconocidas relaciones que entablaron los movimientos anarquistas de los tres países (Margarucci y Godoy Sepúlveda, 2017, 2018 y 2020; Margarucci, 2020).

Uno de los principales hallazgos de esos trabajos tiene que ver con que estas redes de difusión y de intercambio no solo habrían viabilizado, a través de la circulación de activistas y el envío de materiales de propaganda, el desarrollo del anarquismo boliviano. También, habrían funcionado en sentido inverso desde Bolivia, aportando recursos militantes, ideológicos y monetarios a los grupos ácratas de Argentina y Chile. Como los movimientos de personas entre los tres países, se trató de relaciones de ida y de vuelta, igualmente prolíficas, en términos de su impacto, para todos los actores que se involucraron en ellas.

Si bien queda mucho por explorar en este terreno (por ejemplo, avanzar en el trazado de la red que unió entre las décadas de 1920 y 1940 a los anarquistas de Argentina y Bolivia a partir de las vías del tren, desde Buenos Aires, pasando por las principales ciudades del noroeste argentino y el paso fronterizo de La Quiaca) podemos aventurar la siguiente hipótesis.

En el caso boliviano, las redes transnacionales de difusión e intercambio fueron si no más intensas, al menos más determinantes que en otros espacios, para abonar el surgimiento del anarquismo local. Esta importancia puede ser explicada como el resultado combinado de varias particularidades, vinculadas a una serie de aspectos socio-culturales y políticos del proceso histórico particular de este país. En primer lugar, el aislamiento geográfico al que ya aludimos, un sentimiento que los propios anarquistas andinos hicieron explícito. En segundo lugar, las dificultades para editar sus propios materiales de difusión y propaganda, causadas por los altos niveles de represión estatal y el apego de la cultura Aymara y Quechua a una tradición comunicativa esencialmente oral. Aislamiento y dificultades que el movimiento libertario de Bolivia intentó superar, relacionándose con sus vecinos. Del mismo modo, la interrupción de esas redes -transitoria primero durante la Guerra del Chaco, luego definitiva (para el final de la década de 1940)- quizás ayude a comprender, como una variable explicativa entre otras, los procesos de declive y crisis de este movimiento.

En este sentido, para completar el giro, es necesario incorporar las geografías que todavía están en blanco en ese mapa, de modo de poder conectar los espacios disociados que hay en él (por ejemplo, el eje atlántico con el del pacífico). Conexiones que efectivamente existieron en la experiencia histórica pero 
que el nacionalismo metodológico no nos dejó ver, siquiera imaginar. El punto de partida de este ejercicio es más profundo y radical, pues tiene que ver con cuestionar muchas de las categorías analíticas y consensos historiográficos heredados. Lo cual, implica tensionar la idea del anarquismo confinado, ceñido a los límites político-territoriales de un país. Implica también dejar de dar por supuesto que hubo anarquistas en algunos casos nacionales y que en otros, simplemente no existieron.

Buenos Aires, 29 de noviembre de 2019

\section{Bibliografía citada}

Aguirre Rojas, Carlos Antonio (2005). La "Escuela" de los Annales. Ayer, hoy y mañana, México: Contrahistorias.

Albornoz, Martín (2017). “Policías, cónsules y anarquistas: la dimensión transatlántica de la lucha contra el anarquismo en Buenos Aires (1889-1913)", en Iberoamericana. América Latina - España - Portugal, 17 (64), pp. 57-79.

Albornoz, Martín y Galeano, Diego (2017). “Anarquistas y policías en el atlántico sudamericano: una red transnacional, 1890-1910", en Boletín del Instituto de Historia Argentina y Americana "Dr. Emilio Ravignani", 3 (47), pp. 101134.

Albornoz, Martín y Galeano, Diego (2019). “Los agitadores móviles: trayectorias anarquistas y vigilancias portuarias en el Atlántico sudamericano, 1894-1908", en Almanack, 21, pp. 310-357.

Almeida, Paul y Johnston, Hank (2006). Latin American Social Movements: Globalization, Democratization and Transnational Networks, Lanham: Rowman and Littlefield.

Anderson, Benedict (2008). Bajo tres banderas. Anarquismo e imaginación anticolonial, Madrid: Akal.

Baer, James (2015). Anarchist Immigrants in Spain and Argentina, Urbana: University of Illinois Press.

Bantman, Constance (2006). "Internationalism without an International? CrossChannel Anarchist Networks, 1880-1914", en Revue Belge de Philologie et d'Histoire, 84 (4), pp. 961-981.

Bantman, Constance (2013). The French Anarchists in London, 1880-1914: Exile and Transnationalism in the First Globalisation, Liverpool: Liverpool University Press.

Bantman, Constance y Altena, Bert (eds.) (2015). Reassessing the Transnational Turn. Scales of Analysis in Anarchist and Syndicalist Studies, London: Routledge. 
Bantman, Constance y Altena, Bert (eds.) (2017). Reassessing the Transnational Turn. Scales of Analysis in Anarchist and Syndicalist Studies, Oakland: PM Press.

Bantman, Constance y Berry, David (eds.) (2010). New Perspectives on Anarchism, Labour and Syndicalism: The Individual, the National and the Transnational, Newcastle: Cambridge Scholars Publishing.

Becker, Marc (2017). Twentieth-Century Latin American Revolutions, Lanhman: Rowman and Littlefield.

Berti, Giampietro (1975). "Sobre historiografía del anarquismo", en Reconstruir, 99, pp. 47-56.

Bloch, Marc (1924). Les rois thaumaturges, étude sur le caractère surnaturel attribué la puissance royale, particulièrement en France et en Angleterre, Strasbourg et Paris: Librairie Istra.

Bloch, Marc (1992). "Por una historia comparada de las sociedades europeas", en Godoy, Gigi y Hourcade, Eduardo (eds.) Marc Bloch. Una historia viva, Buenos Aires: CEAL, pp. 63-98.

Braudel, Fernand (1949). La Méditerranée et le monde méditerranéen a l'époque de Philippe II, París: Librairie Armand Colin.

Camarero, Hernán y Mangiantini, Martín (2018). El movimiento obrero y las izquierdas en América Latina: experiencias de lucha, inserción y organización, Vols. 1 y 2, Raleigh: A Contra Corriente.

Cappeletti, Ángel (1990). Hechos y figuras del anarquismo hispanoamericano, Madrid-Móstoles: Madre Tierra.

Cappeletti, Ángel y Rama, Carlos (comps.) (1990). El Anarquismo en América Latina, Caracas: Biblioteca Ayacucho.

Chernilo, Daniel (2006). "Social theory's methodological nationalism: Myth and reality", en European Journal of Social Theory, 9 (1), pp. 5-22.

Colectivo editor. (2018). “Editorial: Aniversario y balance. Por una renovación de la agenda historiográfica de las izquierdas", en Políticas de la Memoria, 18, pp. 7-14.

Cunha, Eduardo Souza (2017). "O circuito editorial anarquista de Buenos Aires e suas relações transnacionais (1890-1905)", en XVI Jornadas Interescuelas. Departamentos de Historia, Facultad de Humanidades, Universidad de Mar del Plata, Mar del Plata, 9-11 de agosto.

Cunha, Eduardo Souza (2018). Editar a revolta: edição e circulação de impressos anarquistas em Buenos Aires (1890-1905), Tesis de maestría, Faculdade de Filosofia, Letras e Ciências Humanas, Universidade de São Paulo, São Paulo. 
Cunha, Eduardo Souza (2019). “Fortunato Serantoni y la Librería Sociológica. El circuito editorial en la red transnacional de militancia del anarquismo", en Políticas de la Memoria, 19, pp. 191-213.

Cunha, Eduardo Souza y Godoy, Clayton Peron (2018). “Novos olhares sobre o anarquismo - Entrevista com Davide Turcato", en Revista Latino-Americana de História, 7 (19), pp. 284-295.

De La Guardia, Carmen y Pan-Montojo, Juan (1998). "Reflexiones sobre una historia transicional", en Studia histórica. Historia contemporánea, 16, pp. 9-31.

De Laforcade, Geoffroy (2011). “Federative Futures: Waterways, Resistance Societies, and the Subversion of Nationalism in the Early 20th-Century Anarchism of the Río de la Plata Region", en Estudios Interdisciplinarios de América Latina y El Caribe, 22 (2), pp. 71-96.

De Laforcade, Geoffroy y Shaffer, Kirwin (eds.). (2015). In Defiance of Boundaries: Anarchism in Latin American History, Gainesville, University Press of Florida.

Fernández Cordero, Laura (2017). “El periódico anarquista Nuestra Tribuna. Un diálogo transnacional en América Latina", en Anuario de Estudios Americanos, 74 (1), pp. 267-293.

Giner, Francisca (2011). ¿Internacionalismo obrero o unidad latinoamericana? Las relaciones entre los movimientos obreros de Chile y Argentina en el primer cuarto del siglo XX, Tesis de maestría, Universidad de Chile, Santiago.

Godoy, Clayton Peron (2013). Ação direta: transnacionalismo, visibilidade e latência na formação do movimento anarquista em São Paulo (1892-1908), Tesis de doctorado, Faculdade de Filosofia, Letras e Ciências Humanas, Universidade de São Paulo, São Paulo.

Gómez Müller, Alfredo (2009). Anarquismo y anarcosindicalismo en América Latina: Colombia, Brasil, Argentina y México, Medellín: La Carreta Ediciones.

Guérin, Daniel (1970). Anarchism: from theory to practice, New York: Monthly Review Press.

Guevara, Gustavo (coord.) (2013). Sobre las Revoluciones Latinoamericanas del siglo XX, Buenos Aires: Newen Mapu.

Hirsch, Steven (2010). "Peruvian anarcho-syndicalism: adapting transnational influences and forging counter hegemonic practices, 1905 - 1930", en Hirsch, Steven y Der Walt, Lucien van (eds.) Anarchism and Syndicalism in the Colonial and Postcolonial World, 1870-1940, Leiden and Boston: Brill, pp. 227-271.

Hirsch, Steven (2011). "Without borders: reflection on Anarchism in Latin America", en Estudios Interdisciplinarios de América Latina y El Caribe, 22 (2), pp. 7-10. 
Hirsch, Steven y Der Walt, Lucien van (eds.) (2010). Anarchism and Syndicalism in the Colonial and Postcolonial World, 1870-1940, Leiden and Boston: Brill.

Hobsbawm, Eric (1959). Primitive Rebels: Studies in Archaic Forms of Social Movement in the 19th and 20th Centuries, Manchester: Manchester University Press, 1959.

Iriye, Akira (2013). Global and Transnational History. The Past, Present, and Future, Basingstoke: Palgrave Macmillan.

Iriye, Akira y Saunier, Pierre-Yves (eds.) (2009). The Palgrave Dictionary of Transnational History. From the mid-19th Century to the Present Day, Basingstoke: Palgrave Macmillan.

Keck, Margaret E. y Sikkink, Kathryn (1998). Activists beyond Borders: Advocacy Networks in International Politics, Ithaca, New York: Cornell University Press, 1998.

Klaus Patel, Kiran (2015). “An Emperor without Clothes? The Debate about Transnational History Twenty-five Years On”, en Histoire@Politique, 26, pp. 7887.

Lida, Clara y Yankelevich, Pablo (comps.) (2012). Cultura y política del anarquismo en España e Iberoamérica, México DF, El Colegio de México.

Llaguno, José Julián (2016). “Acción local y auditorio global: la presencia anarquista en América Central según sus fondos documentales entre $1910 \mathrm{y}$ 1930", en Diálogos Revista Electrónica de Historia, 17 (2), pp. 33-51.

Llaguno, José Julián (2019). “Anarquismo trasatlántico: propaganda, polémicas y debates entre España y América Central (1911-1914)", en el II Congreso Internacional de Investigadorxs sobre Anarquismo(s), Facultad de Humanidades y Ciencias de la Educación, Universidad de La República y CeDInCI, Montevideo, 11-13 de julio.

Macdonald, Simon (2013). "Transnational history: a review of past and present scholarship", UCL Centre for Transnational.

Margarucci, Ivanna (2020). “Del Atlántico a los Andes. Notas sobre las relaciones del anarquismo argentino y boliviano, 1922-1927", en Anuario IEHS (en prensa).

Margarucci, Ivanna y Godoy Sepúlveda, Eduardo (2017). “El Centro de Estudios Sociales La Brecha y el internacionalismo ácrata en el Norte Grande (Chile, 1922-1924)", en Historia en Movimiento, Revista de Historia y Ciencias Sociales, 4 (4), pp. 57-69.

Margarucci, Ivanna y Godoy Sepúlveda, Eduardo (2018). Anarquismos en confluencia. Chile y Bolivia durante la primera mitad de siglo XX, Santiago: Eleuterio, 2018. 
Margarucci, Ivanna y Godoy Sepúlveda, Eduardo (2020). “Anarquistas 'en movimiento'. Redes de circulación e intercambio en el Norte Grande, 19001930". Diálogo Andino, Revista de Historia, Geografía y Cultura Andina (en prensa).

Marshall, Peter (1993). Demanding the Impossible: a history of anarchism, London: Fontana Press.

Martins, Herminio (1974). "Time and theory in Sociology", en John Rex (ed.). Approaches to Sociology. An Introduction to Major Trends in British Sociology, London: Routledge \& Kegan, pp. 246-294.

Mazlish, Bruce (1998). "Comparing Global History to World History", en Journal of Interdisciplinary History, 28 (3), pp. 385-395.

Mazlish, Bruce y Buultjens, Ralph (1993). Conceptualizing global history, Boulder: Westview Press.

Méndez Pacheco, Nelson (2012). "Anarquismo en América Latina: consideraciones en torno a su Historia, Rasgos y Perspectivas", en Estudios. Revista de Pensamiento Libertario, 2, pp. 129-141.

Migueláñez Martínez, María (2013). “Diego Abad de Santillán (1897-1983): los viajes doctrinarios de un anarquista transnacional", en Pérez Ledesma, Manuel (ed.) Trayectorias trasatlánticas (Siglo XX): personajes y redes entre España y América, Madrid: Polifemo, 2013, pp. 163-198.

Migueláñez Martínez, María (2013a). “La presencia argentina en la esfera del anarquismo y el sindicalismo internacional: las luchas de representación", Historia, Trabajo y sociedad, 4, pp. 89-117.

Migueláñez Martínez, María (2014). “El proyecto continental del anarquismo argentino: resultados y usos de una propaganda transfronteriza", Ayer, 94, pp. 71-94.

Migueláñez Martínez, María (2014a). "Atlantic Circulation of Italian Anarchist Exiles: Militants and Propaganda between Europe and Río de la Plata (19221939)", Zapruder World: An International Journal for the History of Social Conflict, 1.

Migueláñez Martínez, María (2018). Más allá de las fronteras: el anarquismo argentino en el periodo de entreguerras. Tesis de doctorado, Universidad Autónoma de Madrid.

Morales Moya, Antonio (1992). "Historia y postmodernidad", en Ayer, 6, pp. 1538

Morcillo Espina, Álvaro (2011). “El debate entre transnacionalismo y nacionalismo metodológico como marco teórico para la comprensión del papel del empleo en la gobernabilidad de la inmigración en España", en Papers, 96 (3), pp. 757-780. 
Nettlau, Max (1972). “Viaje libertario a través de la América Latina”, en Reconstruir, 76, 77 y 78.

Nettlau, Max (1975). Contribución a la bibliografía anarquista de la América Latina hasta 1914, London: C. Slienger.

Pipitone, Ugo (2015). La esperanza and el delirio: Una historia de la izquierda en América Latina, México DF: Centro de Investigación y Docencia Económicas/Taurus.

Sánchez Cobos, Amparo (2013). "Estrechando lazos. Cuba y España en las redes anarquistas internacionales (1900-1925)", en Alcores: Revista de Historia Contemporánea, 15, pp. 89-110.

Savala, Joshua (2019). "Ports of Transnational Labor Organizing: Anarchism along the Peruvian-Chilean Littoral, 1916-1928", en Hispanic American Historical Review, 99 (3), pp. 501-531.

Seigel, Micol (2005). "Beyond Compare: Comparative Method after the Transnational Turn", en Radical History Review, 2005 (91), pp. 62-90.

Shaffer, Kirwin (2011). "Contesting Internationalists: Transnational Anarchism, Anti-Imperialism and US Expansion in the Caribbean, 1890s-1920s", en Estudios Interdisciplinarios de América Latina y El Caribe, 22 (2), pp. 11-38.

Shaffer, Kirwin (2014). "Latin Lines and Dots: Transnational Anarchism, Regional Networks, and Italian Libertarians in Latin America," en Zapruder World: An International Journal for the History of Social Conflict, 1.

Simon, Fanny (1946). "Anarchism and Anarcho-Syndicalism in South America" en The Hispanic American Historical Review, 26 (1), pp. 38-59.

Smith, Anthony (1979). Nationalism in the Twentieth Century, Oxford, Martin Robertson / New York, University Press.

Stoessel, Soledad (2014). "Giro a la izquierda en la América Latina del siglo XXI", en Polis [En línea], 39, 2014. Disponible en $<$ http://journals.openedition.org/polis/10453>. Fecha de consulta: 08/11/2019.

Subrahmanyam, Sanjay (1997). "Connected Histories: Notes towards a Reconfiguration of Early Modern Eurasia", en Modern Asian Studies, 31 (3), pp. 735-762.

Tinsman, Heidi (2011). “Los Estudios latinoamericanos y el giro transnacional," en AAVV, Cátedra Norbert Lechner, Santiago, Ediciones Diego Portales, pp. 7597.

Turcato, Davide (2007). "Italian Anarchism as a Transnational Movement, 18851915", en International Review of Social History, 52 (3), pp. 407-444.

Turcato, Davide (2012). Making Sense of Anarchism: Errico Malatesta's Experiments with Revolution, 1889-1900, Basingstoke: Palgrave Macmillan. 
Van der Linden, Marcel (1993). "Editorial", en International Review of Social History, 38 (1), pp. 1-3.

Van der Linden, Marcel (2002). "Globalizing Labour Historiography: The IISH Approach", International Institute of Social History.

Van der Linden, Marcel (2008). Workers of the World: Essays toward a Global Labor History, Leiden, and Boston: Brill.

Viana, Rafael (2018). Um anarquismo latino-americano: Estudo comparativo e transnacional das experiências na Argentina, Brasil E Uruguai (1959-1985), Tesis de doctorado, Universidad Federal Rural do Rio de Janeiro.

Viñas, David (1983). Anarquistas en América Latina, México: Katún.

Vitale, Luis (1998). Contribución a una historia del anarquismo en América Latina, Santiago: Instituto Pedro Vuskovic.

Weinstein, Barbara; Abbattista, Lucía y Starcenbaum, Marcelo, tr. (2013), “Pensando la historia más allá de la nación: La historiografía de América Latina y la perspectiva transnacional", en Aletheia [En línea], 3 (6). Disponible en <http://www.memoria.fahce.unlp.edu.ar/art revistas/pr.6118/pr.6118.pdf $>$. Fecha de consulta: 08/11/2019.

Werner, Michael y Zimmerman, Bénédicte (2003). "Penser l'histoire croisée: entre empirie et réflexivité", en Annales. Histoire, Sciences Sociales, 58 (1), pp. 538.

Woodcock, George (1962). Anarchism: a history of libertarian ideas and movements, Cleveland and New York: The World Publishing Company. 